\title{
The prevention of deformity in intertrochanteric fractures of the femur
}

\author{
E. N. WardLE \\ M.Ch.Orth., F.R.C.S. \\ Department of Orthopaedic Surgery, \\ University of Liverpool
}

Although the first recorded mention of internal fixative apparatus for the treatment of intertrochanteric fractures was made by Preston in 1914 , it was not until the decade 1935-45 that devices of this kind came into common use. This sudden interest probably arose because of the great general benefit which patients with subcapital fractures of the femur were seen to obtain from the same type of procedure.

Among the many articles published subsequently all those which contain radiographs of any lengthy series of patients show examples of intertrochanteric fractures which have collapsed into varus deformity during their union; and in many instances disruption of the metal device also (Murray \& Frew, 1949; Boyd \& Griffin, 1949; Evans, 1951; McLaughlin \& Garcia, 1955; Taylor, Neufeld \& Nickel, 1955 ; Foster, 1958). The illustration (Fig. 1) displays this type of collapse and disruption. A study of these deformities shows that they are nearly always associated with intertrocanteric fractures in which the lesser trochanter is separated, or at least involved in the fracture line. Several authors have referred to this particular type of intertrochanteric fracture as unstable.

In the years which have passed since the description by Taylor, Neufeld \& Jantzen (1944) of the nail plate which bears the name of Nuffield, much time and ingenuity have been spent in designing internal fixative apparatus strong enough to prevent such deformity occurring, with particular reference to early movement and weightbearing for these elderly patients (McLaughlin, 1947 ; Hafner, 1951; McLaughlin \& Garcia, 1955; Holt, 1963 ; Sarmiento, 1963). During this period, on the contrary, little interest has been shown in the possibility that the cause of this varus deformity is muscle imbalance, not faulty apparatus. In 1962, together with Murray Brookes (Brookes \& Wardle, 1962), I drew attention to the changes in shape of the upper femur which muscle imbalance can produce when the bone is softened from any cause. It was calculated that in order to prevent ilio-psoas force producing valgus deformity in the femoral neck an opposed 'varusproducing' gluteal force required to be applied to the greater trochanter in the ratio ilio-psoas, five: gluteii, three. So that in any intertrochanteric fracture until union is present, unbalanced gluteal muscular force can act on the proximal fragment in proportion to the disintegration which the fracture has produced in the trochanter and neck of the femur; and in those fractures where the lesser trochanter is completely separated the whole of the abductor force, quite unbalanced, is acting on the proximal fragment. It is of some interest to note that McLaughlin in his original paper in 1947, describing his apparatus for fixation of these fractures barely mentions the occurrence of varus deformity; but in writing with Garcia in 1955 he condemns his original apparatus out of hand on account of the high rate of post-operative deformity, and describes yet a further model in the effort to prevent this.

\section{Clinical material}

Certain groups of patients have been selected.

(a) Five representative patients in whom an intertrochanteric fracture associated with avulsion of the lesser trochanter has been reduced and fixed by a nail and plate. All of them illustrate collapse into deformity, but they show that this may take different forms. Where one-piece apparatus of the Neufeld type has been used the varus deformity is associated either with bending of the nail or disruption of the screws and plate from the femoral shaft. Where two-piece apparatus has been used there is much less tendency for the plate or screws to alter their position in relation to the distal fragment but the deformity of the head and neck occurs around the nail which is thus left protruding into the hip joint. Occasionally with the earlier forms of two-piece apparatus the holding bolt would unscrew from the nail and deformity occurs around the bracket. It is clear from comparison of 
the first and last films in any of these fractures that the final deformity often approximates closely to that present before the fracture was reduced (Figs. 2-5).

(b) From a consecutive series of forty intertrochanteric fractures coming under my care in the period January 1962 to January 1966, fifteen have been chosen in all of whom the fracture was either associated with complete separation of the lesser trochanter as a fragment, or the fracture line has passed directly through the lesser trochanter. In four of these patients at the time of reduction of their fracture and its fixation with a nail and plate the lesser trochanter was fixed to the femoral shaft by means of a screw. In eleven of them, at the time of reduction and fixation, the attachments of the gluteus medius and minimus to the greater trochanter were divided (Table 1). There was no

TABLE 1

Fifteen patients with intertrochanteric fractures

\begin{tabular}{lrrr}
\hline $\begin{array}{c}\text { Treatment and } \\
\text { name }\end{array}$ & Age & Date of fracture & Date of fixation \\
\hline $\begin{array}{l}\text { Treated by screw fixation } \\
\text { Miss D.H. }\end{array} 59$ & 2 Jan. 1962 & 9 Jan. 1962 \\
Mrs F.P. & 81 & 13 Jan. 1961 & 17 Jan. 1961 \\
Mrs E.F. & 90 & 13 Aug. 1961 & 22 Aug. 1961 \\
Mrs M.G. & 65 & 3 Nov. 1961 & 14 Nov. 1961 \\
\hline
\end{tabular}

Treated by gluteal section

$\begin{array}{llrr}\text { Mrs M.C. } & 56 & \text { 16 Jan. } 1962 & \text { 18 Jan. } 1962 \\ \text { Mrs S.M. } & 78 & \text { 4 Feb. } 1962 & \text { 6 Feb. } 1962 \\ \text { Mr W.F. } & 78 & \text { 26 Dec. } 1962 & \text { 30 Dec. } 1962 \\ \text { Mr R.W. } & 83 & \text { 29 Dec. } 1962 & \text { 1 Jan. 1963 } \\ \text { Mrs E.W. } & 77 & \text { 1 Jan. 1963 } & \text { 15 Jan. 1963 } \\ \text { Mr J.S. } & 82 & \text { 23 Jan. } 1963 & \text { 29 Jan. 1963 } \\ \text { Mr H.T. } & 69 & \text { 11 Dec. } 1963 & \text { 19 Dec. 1963 } \\ \text { Miss D.B. } & 53 & \text { 3 Dec. } 1964 & \text { 9 Dec. 1964 } \\ \text { Mrs G.S. } & 61 & \text { 18 Dec. } 1964 & \text { 21 Dec. 1964 } \\ \text { Miss B.B. } & 76 & \text { 9 April 1965 } & \text { 19 April 1965 } \\ \text { Mrs E.R. } & 65 & \text { 4 Jan. 1963 } & \text { 8 Jan. } 1963\end{array}$

operative mortality amongst these patients although several of them have since died from natural causes. All of them survived a sufficient length of time to walk upon the injured leg and to demonstrate firm bony union at the fracture site. In none of them did significant varus deformity appear and in no case did the internal fixative apparatus break down. Table 1 shows that in age, sex and general condition they were fully representative of this type of intertrochanteric fracture seen routinely in any orthopaedic service. None of them was allowed to bear weight until the 6 th post- operative week but they were all encouraged in active non-weight bearing movement of the injured limb as soon as they wished and all of them were sitting out of bed within a week from the time of their operation. It was notable that all of them established a range of active abduction at the injured hip with ease and that all the hips were stable as soon as weight-bearing was commenced (Figs. 6-12).

\section{Discussion}

Assuming that the deformity occurring during the union of intertrochanteric fractures, as illustrated, arises because of the disturbance of the normal balance of muscular forces around the hipjoint, and recognizing that this force is sufficiently powerful to bend metal nails and break or disrupt screws, two possible methods of prevention present themselves. First of all a re-balance of the muscular power by the direct re-attachment of the lesser trochanter in its normal position. Secondly a re-balance of muscular power by the deliberate temporary obliteration of the abductor pull. Radiographs (Figs. 6-12) illustrate that both these methods are effective. The first, re-fixation of the lesser trochanter, is technically difficult and prolongs the operative time in a patient who is usually aged and in a poor state of general health. Either a guide has to be positioned through the upper femoral shaft into the lesser trochanter by X-ray control, which is very time-consuming; or a considerable exposure of the hip-joint area is required through a posterior type of approach. This adds greatly to the general upset of an aged patient. The second, temporary ablation of the attachments of gluteus medius and minimus to the greater trochanter is in effect a tenotomy. It may be simply performed through a 2 in. extension of the lateral approach commonly used for nail-plate operations. As in tenotomies in other parts of the body, union is certain and effective muscle power rapidly restored in a few weeks' time. Such a temporary ablation of the abductor muscle action at the hip-joint necessarily prevents weight-bearing on the injured limb for a period of 4-5 weeks and the results are sufficiently and consistently good to raise the question of whether early weight-bearing is of any value at all in the rehabilitation of these elderly patients. None of the patients here recorded has suffered in any way from this prevention of weight-bearing. Such a prohibition is not to be confused with the establishment of early movement both at the knee and the hip. Two points of interest arise here. First of all that the patients treated by gluteal section have developed active non - weight - bearing movements as rapidly as patients whose fractures have simply been nailed and plated. Secondly, the movement of active 


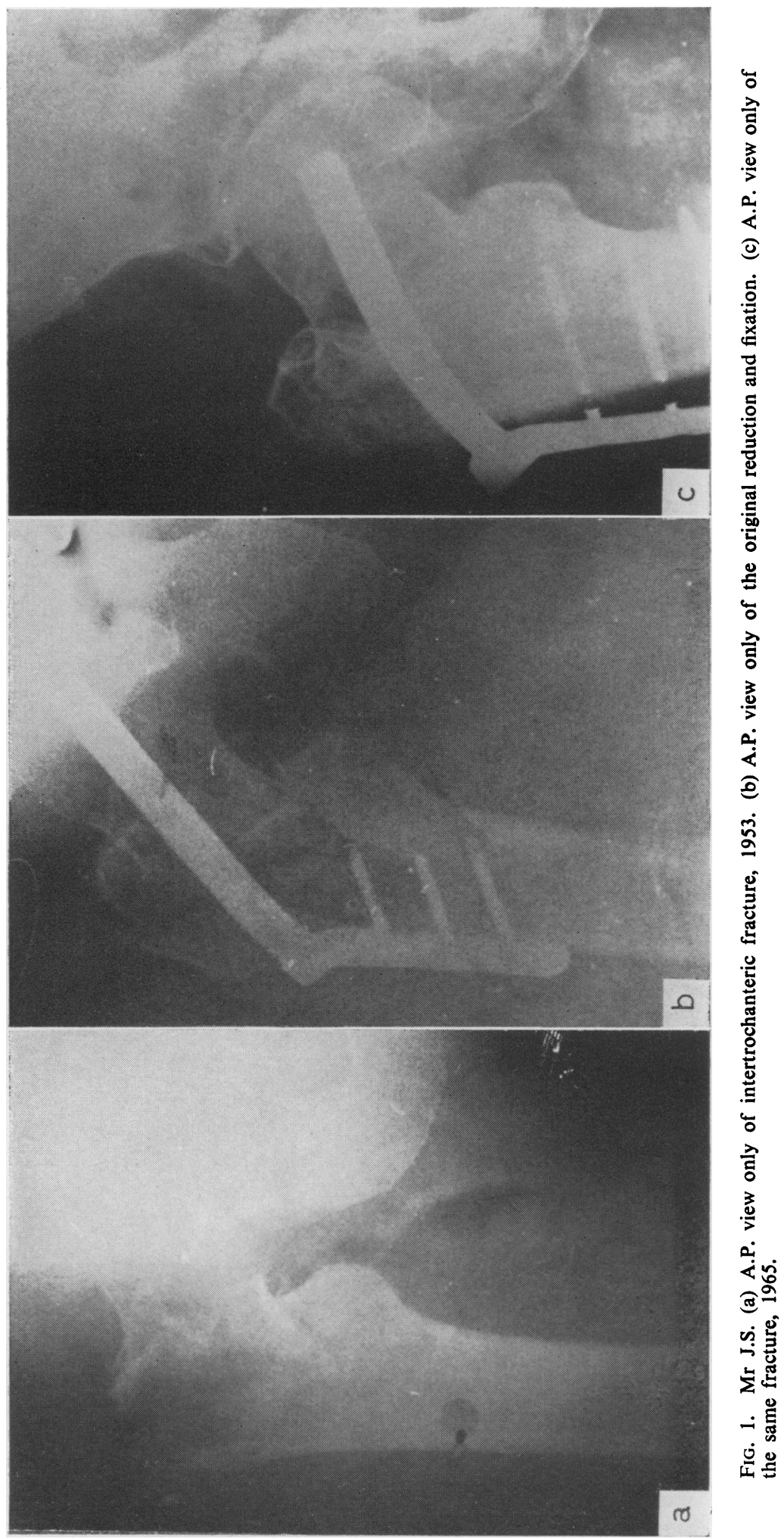




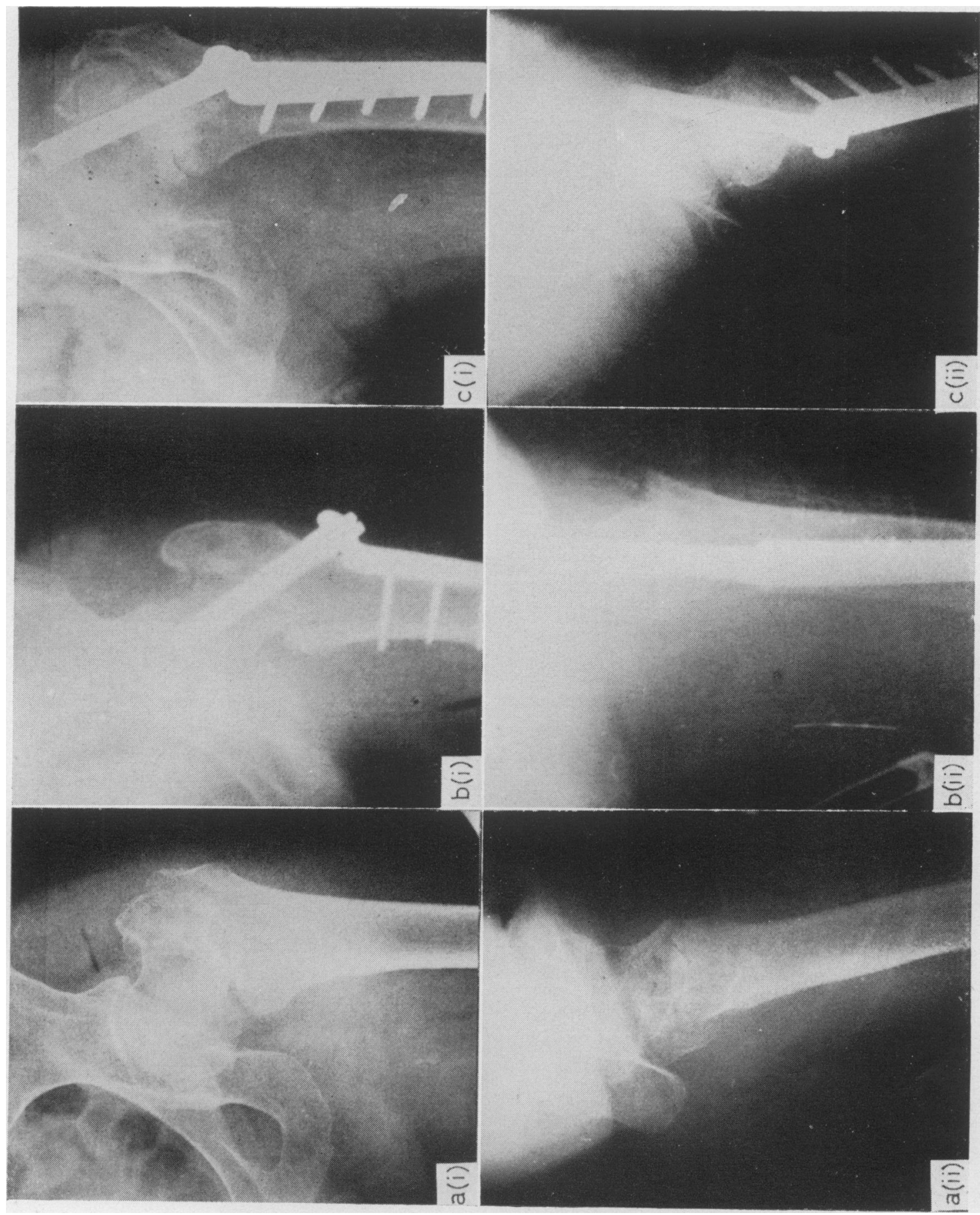




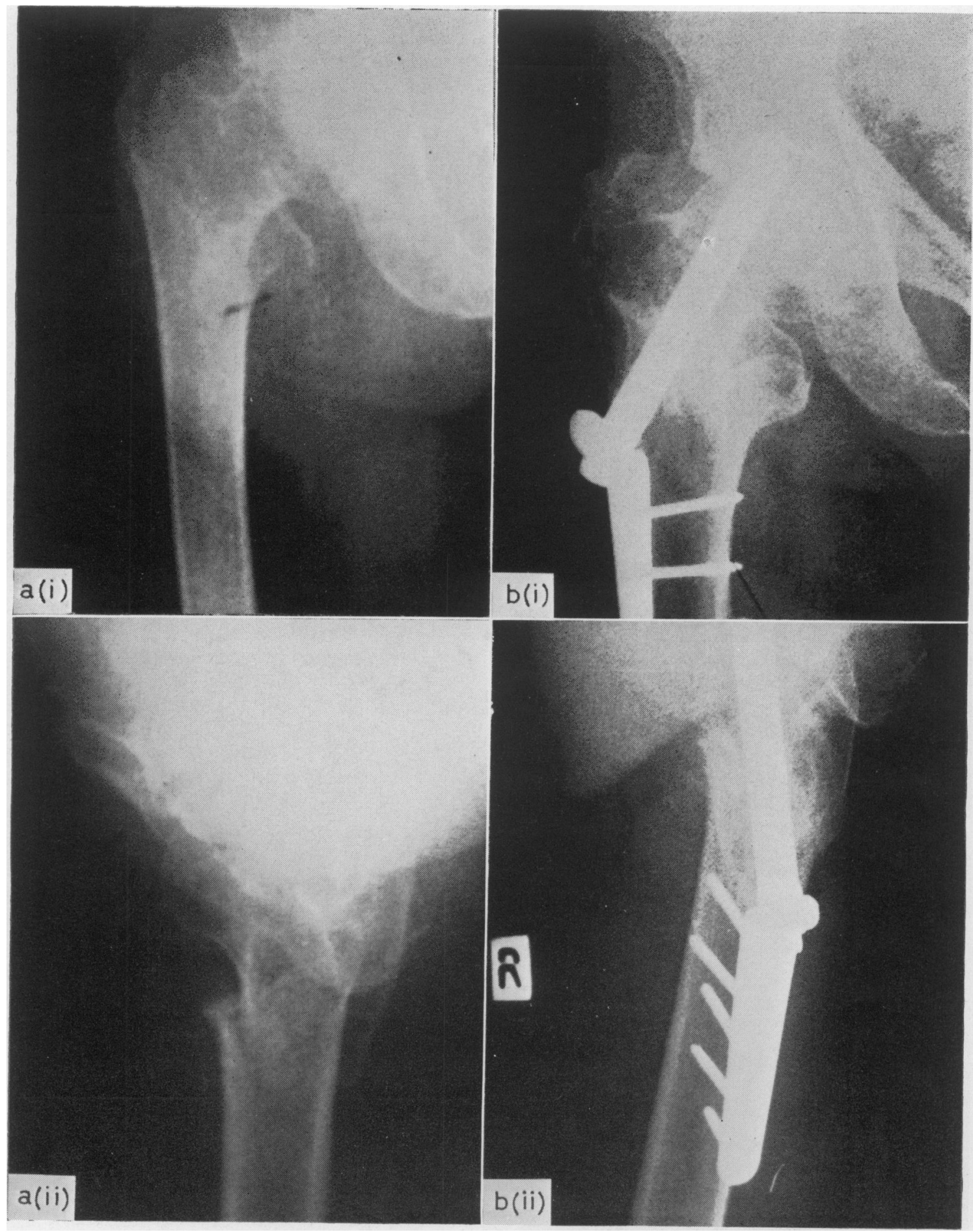

FiG. 3. Mr G.J. (a) A.P. and lateral views of intertrochanteric fracture, 1962. (b) A.P. and lateral views of deformity, 1964. 


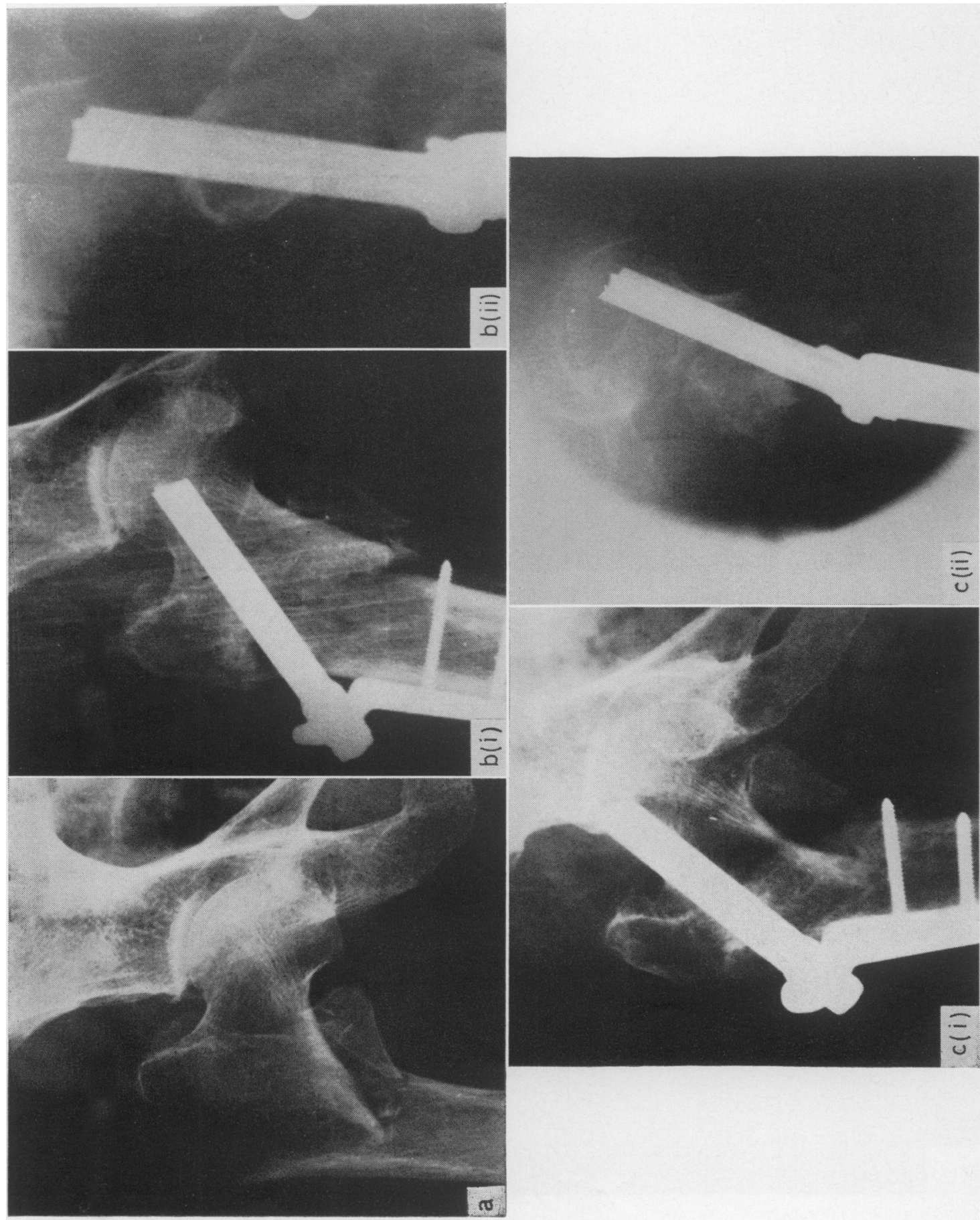




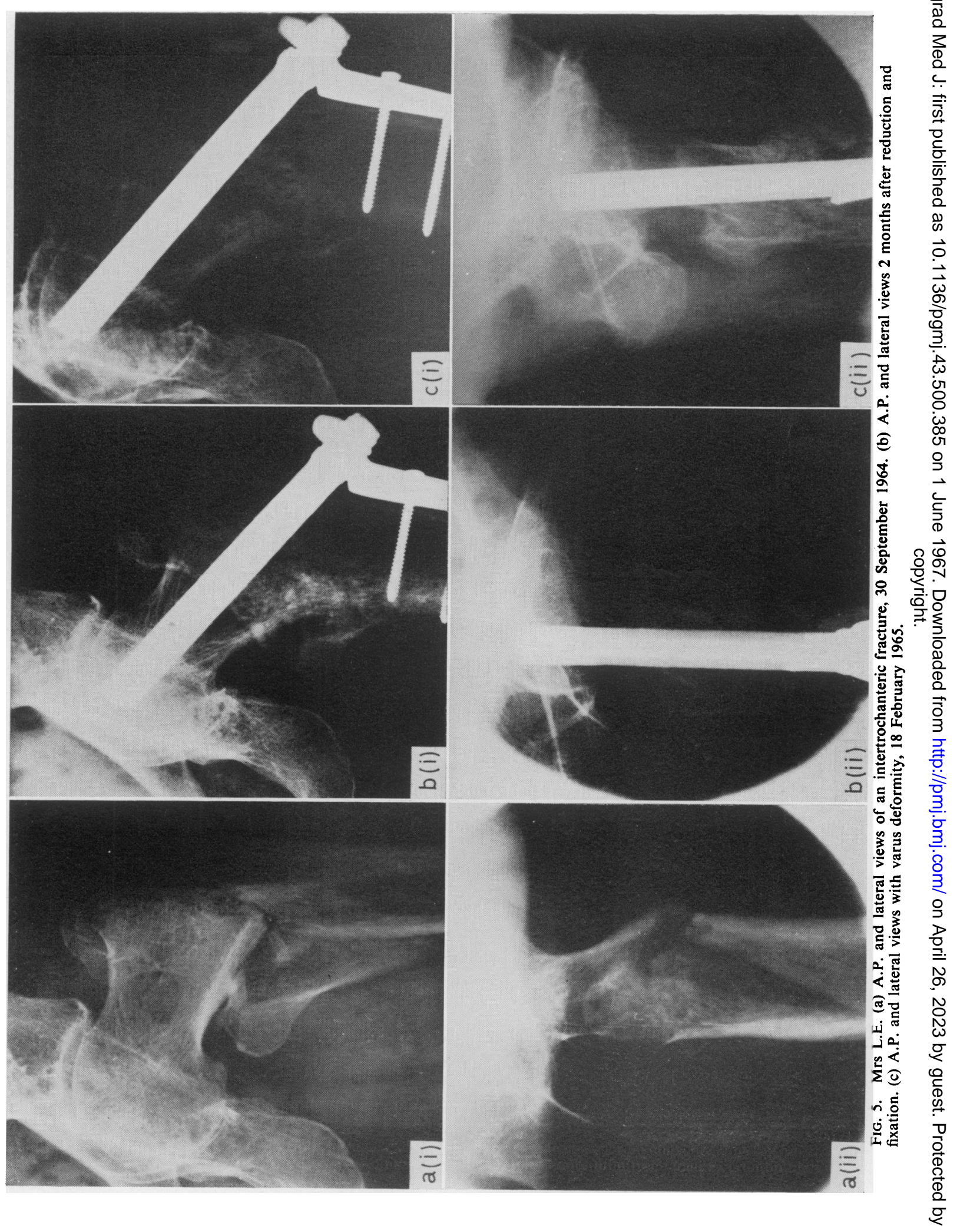




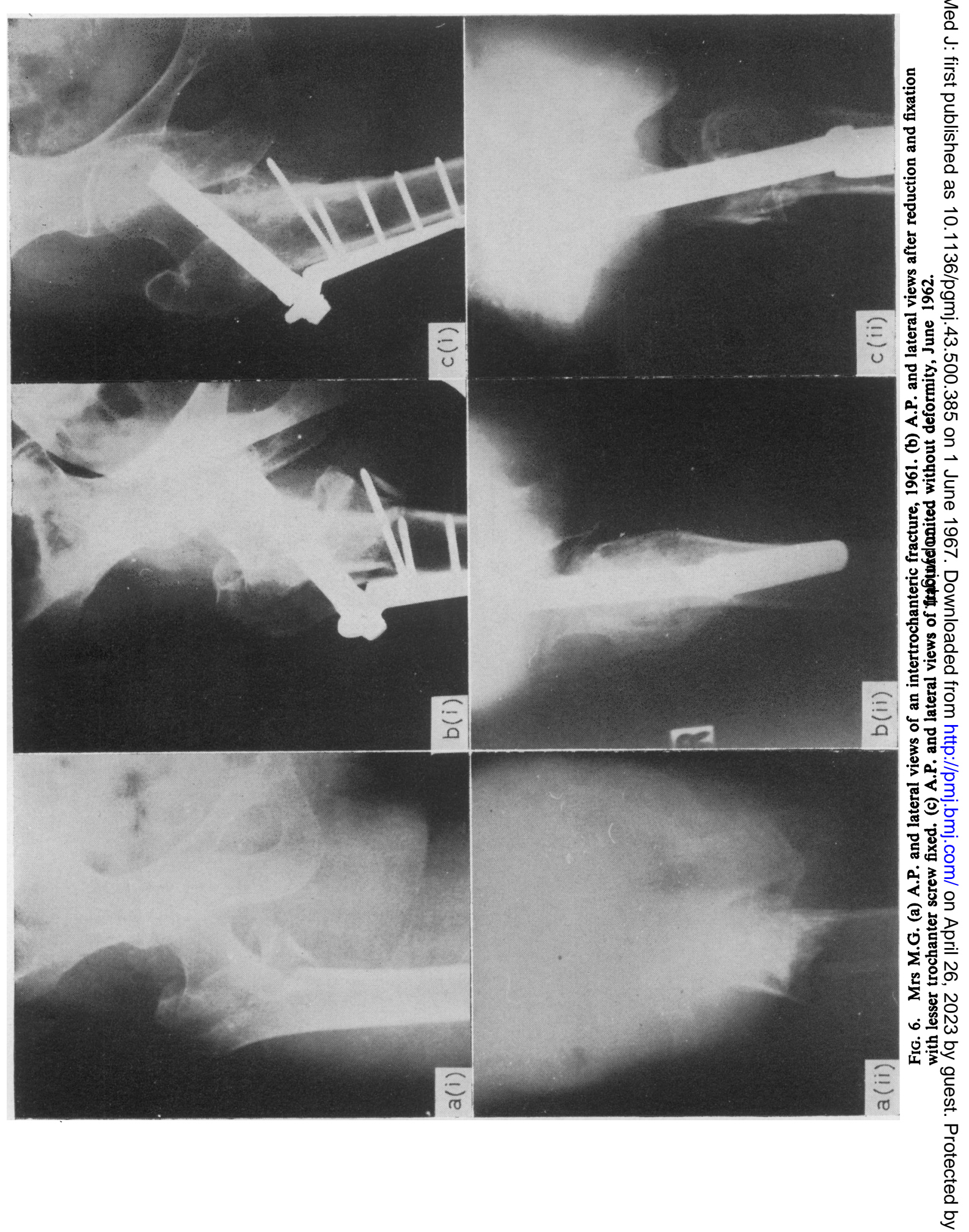




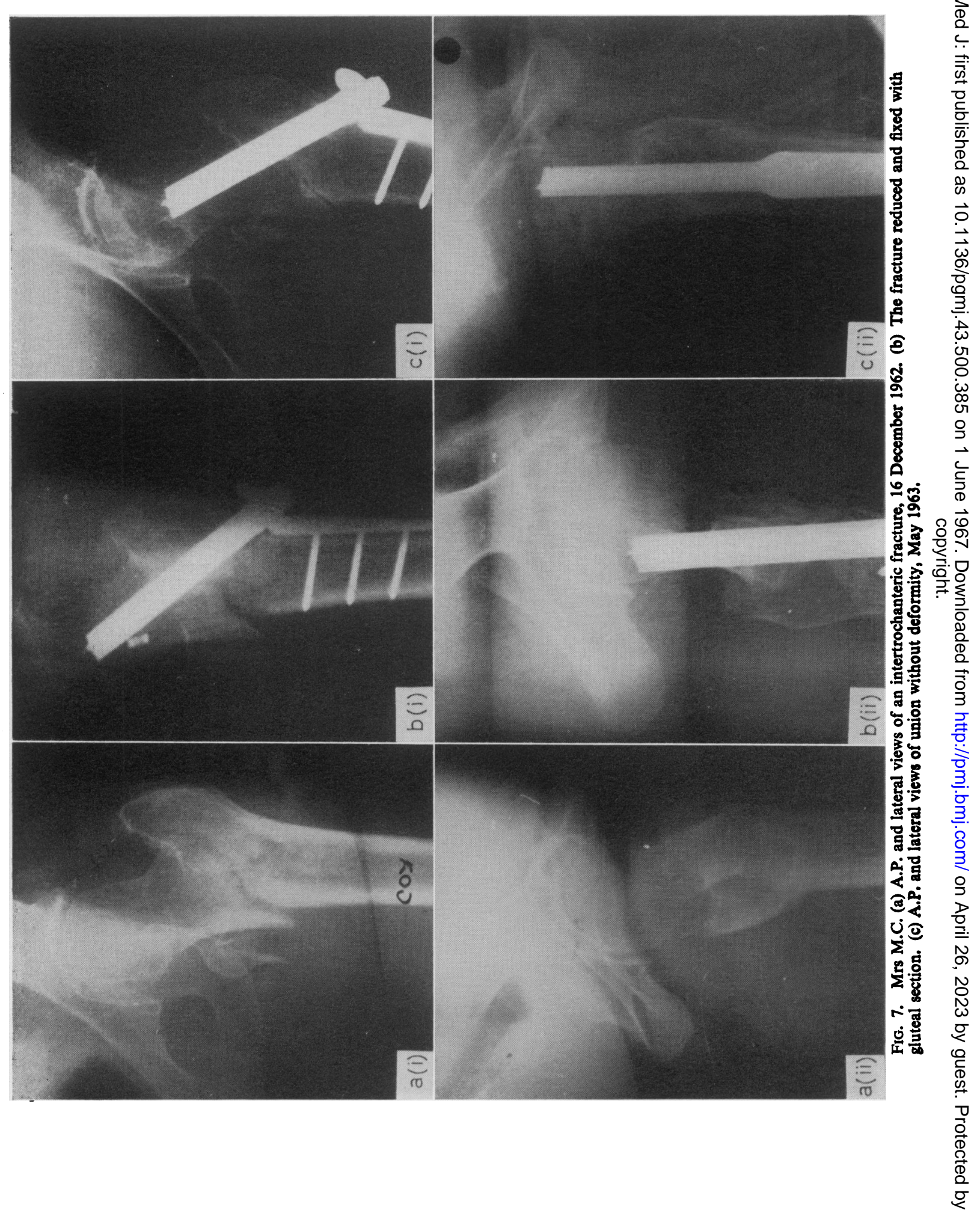




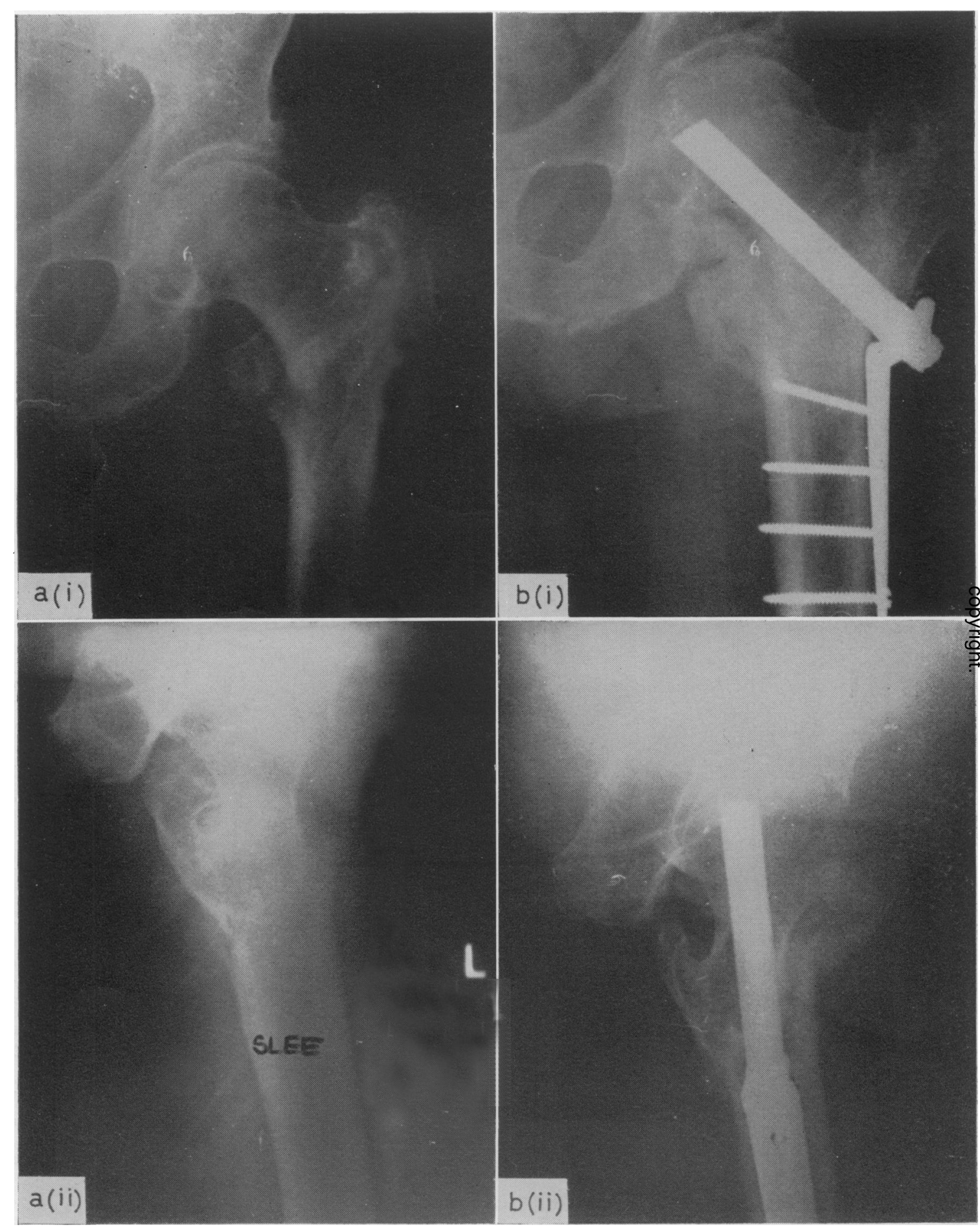

Fig. 8. Mr J.S. (a) A.P. and lateral views of an intertrochanteric fracture, January 1963. (b) A.P. and lateral views of fracture united without deformity 6 months after reduction, fixation and gluteal section. 


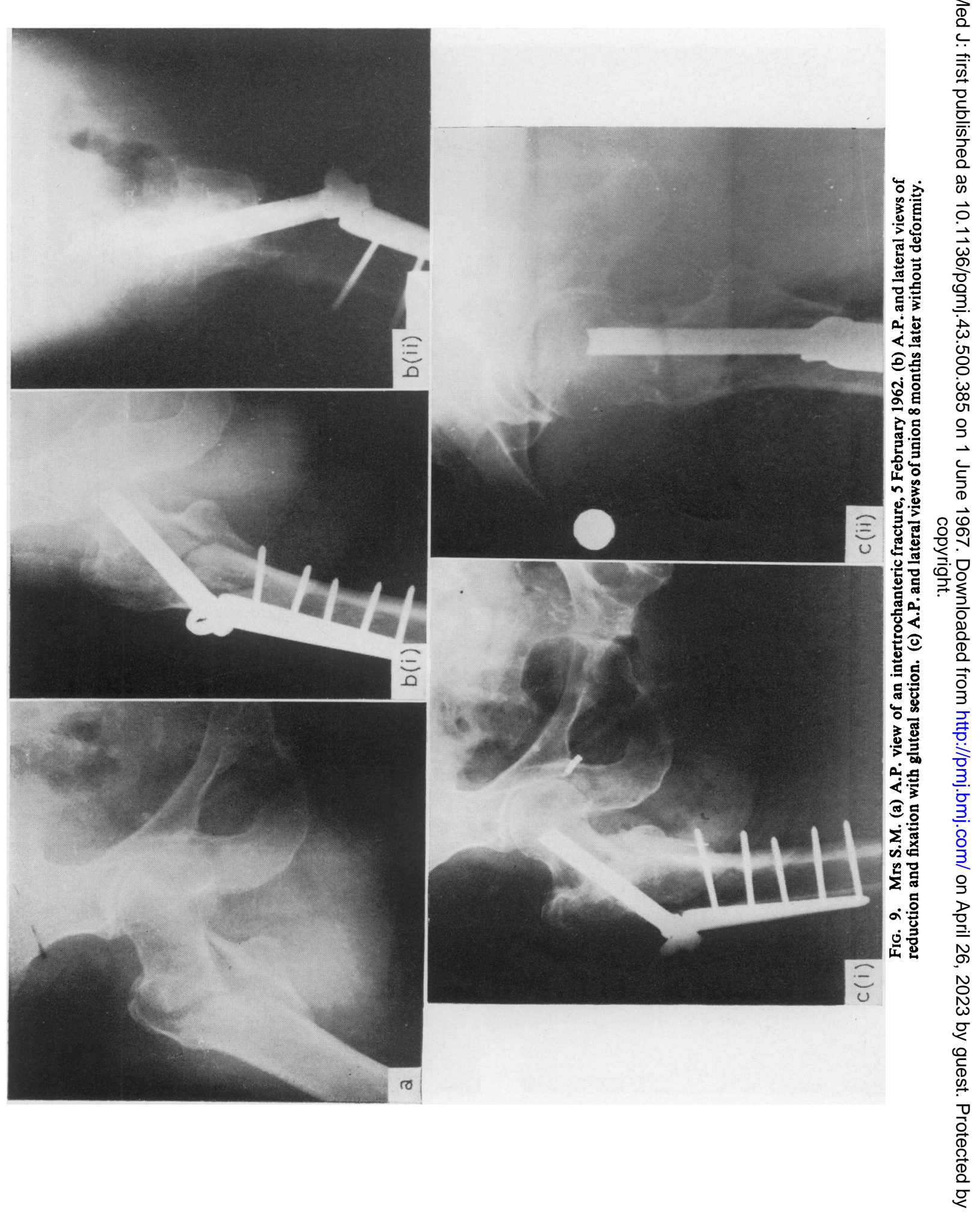




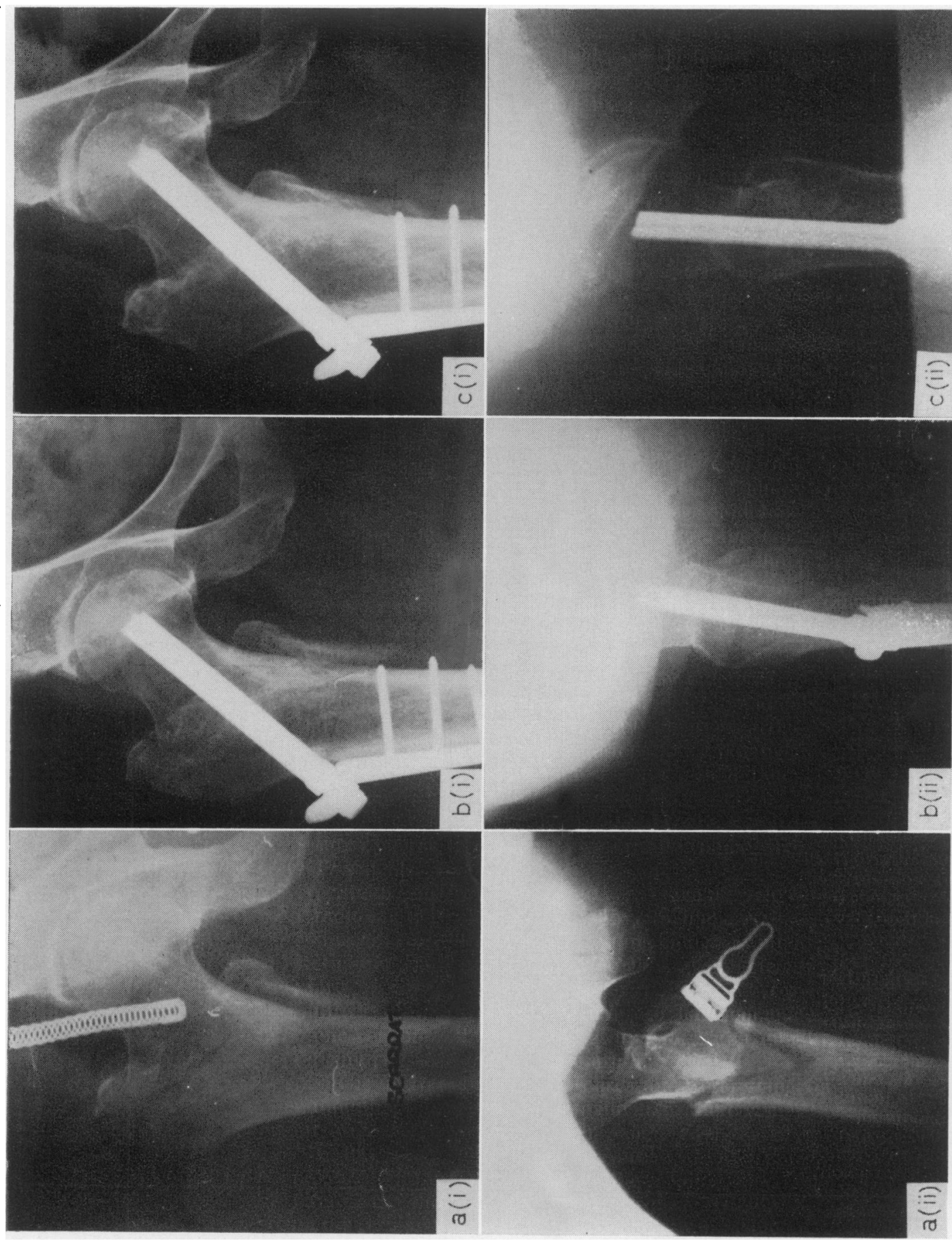

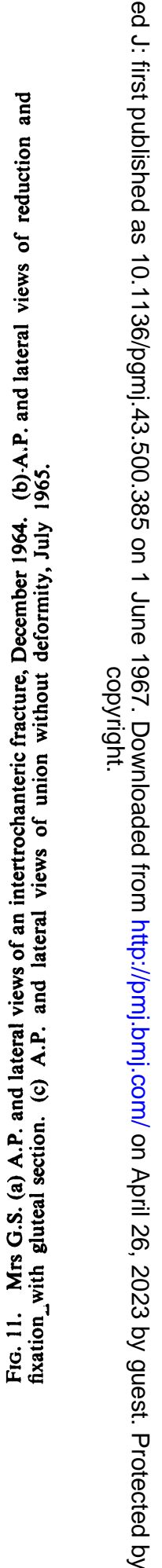




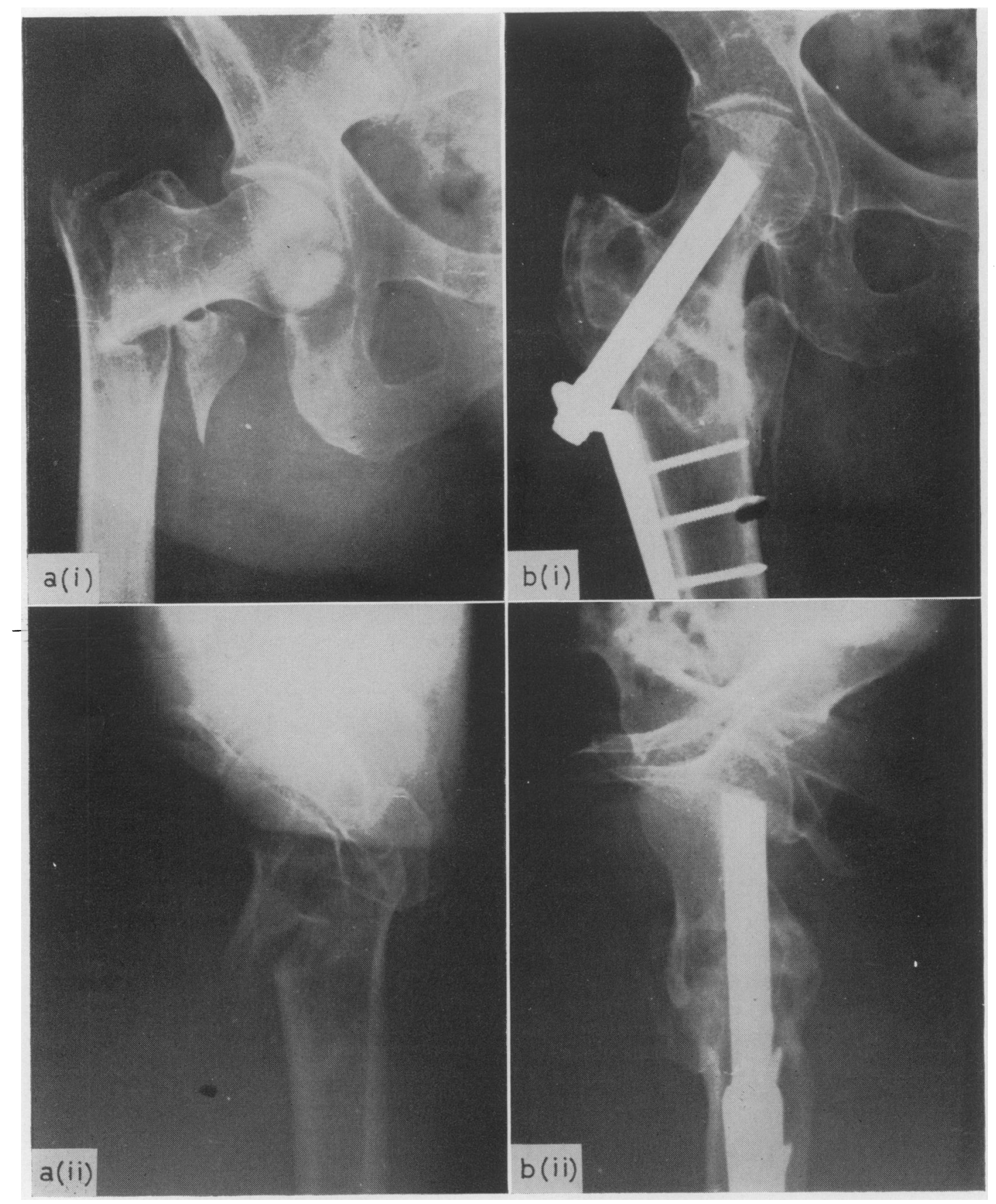

Fig. 12. Mrs E.R. (a) A.P. and lateral views of an intertrochanteric fracture, 4 January 1963. (b) A.P. and lateral views of union without deformity, 20 October 1965. 
flexion at the hip-joint is the one most likely to cause the screw-threaded bolt in the older type of nail plate to undo itself. This movement of active flexion of the hip, done as a deliberate exercise, is the one which should be delayed longest of all. Much less emphasis should be placed on having these patients walk early than has previously been the case although every effort should be made to have them sitting out of bed in a chair as soon as possible.

\section{Summary}

(1) Evidence is produced to show that varus deformity in intertrochanteric fractures is produced by the muscle imbalance inherent in the fractures in which the insertion of the psoas muscle is involved.

(2) This imbalance can be corrected by simple detachment of the gluteii from the greater trochanter which is effective for sufficient time to allow union without deformity and produces no disability.

(3) It is suggested that further strengthening of internal fixative apparatus defeats its own object.

(4) However strong the apparatus, early weight-bearing before bony union is firm causes the muscles to exert a force which no metal can stand.

\section{Acknowledgments}

I am most grateful to my colleague, Professor Robert Roaf, for his criticism and encouragement. I offer my grateful thanks to $\mathrm{Mr} \mathrm{H}$. O. Williams who has allowed me to include several of his patients in Figs. 2 and 3 ; and to my registrar, Mr David Habib, who collected the case notes and X-ray photographs of my own patients.

\section{References}

Boyd, H.B. \& Griffin, L.L. (1949) Classification and treatment of trochanteric fractures. Arch. Surg. 58, 853.

Brookes, M. \& Wardle, E.N. (1962) Muscle action and the shape of the femur. J. Bone Jt Surg. 44-B, 398.

Evans, E.M. (1951) Trochanteric fractures: A review of 110 cases treated by nail-plate fixation. J. Bone Jt Surg. 33-B, 192.

Foster, J.C. (1958) Trochanteric fractures of the femur treated by the Vitallium McLaughlin nail and plate. J. Bone Jt Surg. 40-B, 684 .

HafNer, R.H.V. (1951) Trochanteric fractures of the femur. A review of 80 cases with a description of the 'low-nail' method of internal fixation. J. Bone Jt Surg. 33-B, 513.

HolT, E.P. (1963) Hip fractures in the trochanteric region: treatment with a strong nail and early weight bearing. J. Bone Jt Surg. 45-A, 687.

McLaughlin, H.L. (1947) An adjustable internal fixation element for the hip. Amer. J. Surg. N.s. 73, 150.

McLaughlin, H.L. \& Garcia, A. (1955) An adjustable fixation device for the hip. Amer. J. Surg. 89, 867.

Murray, R.C. \& Frew, J.F.M. (1949) Trochanteric fractures of the femur. J. Bone Jt Surg. 31-B, 204.

Preston, M.E. (1914) New appliance for the internal fixation of fractures of the femoral neck. Surg. Gynec. Obstet. 18, 260.

TAYlor, G.M., Neufeld, A.J. \& JAntzen, J. (1944) Internal fixation for intertrochanteric fractures. J. Bone Jt Surg. 26, 707.

TAylor, G.M., Neufeld, A.J. \& Nickel, V.L. (1955) Complications and failures in the operative treatment of intertrochanteric fractures of the femur. J. Bone Jt Surg. 37-A, 306.

SARmiento, A. (1963) Intertrochanteric fractures of the femur. 150-degree angle nail-plate fixation and early rehabilitation. J. Bone Jt Surg. 45-A, 706. 